\title{
Article \\ Study on the Certification Policy of Zero-Energy Buildings in Korea
}

\author{
Yeweon Kim and Ki-Hyung Yu * \\ Department of Living and Built Environment Research, Korea Institute of Civil Engineering and Building \\ Technology, Ilsan 411-712, Korea; yeweon.kim@kict.re.kr \\ * Correspondence: raytrace@kict.re.kr; Tel.: +82-2-910-0347
}

Received: 20 April 2020; Accepted: 17 June 2020; Published: 24 June 2020

\begin{abstract}
This study presents a methodology and process to establish a mandatory policy of zero-energy buildings (ZEBs) in Korea. To determine the mandatory level to acquire the rating of a ZEB in Korea, this study was conducted under the assumption that the criteria of ZEB was a top 5\% building considering the building's energy-efficiency rating, which was certified through a quantitative building energy analysis. A self-sufficiency rate was also proposed to strengthen the passive standard of the buildings as well as to encourage new and renewable energy production. Accordingly, zero-energy buildings (ZEBs) in Korea are defined as having $60 \mathrm{kWh} /\left(\mathrm{m}^{2} \cdot \mathrm{yr}\right)$ of non-renewable primary energy (NRPE) consumption in residential buildings and $80 \mathrm{kWh} /\left(\mathrm{m}^{2} \cdot \mathrm{yr}\right)$ in non-residential buildings, and the self-reliance rate should be more than $20 \%$ of the renewable energy consumption as compared to the total energy consumption of the buildings. In addition, the mandatory installation of building energy management systems (BEMS) was promoted to investigate the energy behavior in buildings to be certified as zero-energy in the future. This study also investigated the number of ZEB certificates during the demonstration period from 2017 to 2019 to analyze the energy demand, non-renewable primary energy, renewable primary energy, and self-sufficiency rate as compared to those under the previous standards. For ZEB Grade 1 as compared to the existing building energy-efficiency rating, the sum of the NRPE decreased more than $50 \%$, and renewable energy consumption increased more than four times.
\end{abstract}

Keywords: zero-energy building (ZEB), building energy policy; self-sufficiency rate; certification criteria of ZEBs

\section{Introduction}

\subsection{Background of the Study}

As greenhouse gas emissions have emerged as an important issue in the building sector, nations around the world have implanted various policies and systems to promote energy efficiency. In particular, a mandatory minimum level required for energy efficiency in new buildings has been enforced and a mandatory zero-energy building (ZEB) level, which is defined according to each nation, will be targeted by 2020. Accordingly, Korea has led the way and started mandatory ZEB construction from 2017 [1].

\subsection{Current Status of Energy Building Policies Overseas}

European Union (EU) nations established and executed a target goal and published detailed criteria in accordance with their circumstances based on the energy performance of buildings. In 2010, the adoption of the Energy Performance of Buildings Directive-EBPD, Directive 2010/31/EU—presented the building industry in the member states (MSs) with new challenges. 
One of the most prominent among them, as far as new buildings are concerned, is the progress towards nearly zero-energy buildings (NZEBs) by 2021 (or, in the case of public buildings, by 2019) [2] . Denmark established the Energy Policy Vision 2025, by which the proportion of new and renewable energy (NRE) accounts for up to $30 \%$ of all energy consumption. Consumers who use more than $100 \mathrm{MWh} / \mathrm{yr}$. must install a smart meter. Although no mandatory regulations for residential customers have been made, Denmark has provided guidelines for remote metering [3]. Germany has applied building energy-saving design criteria since 2002 after acquiring approval of the Energy Saving Act under the Energy Saving Ordinance (EnEV) issued by the federal government. The Act was revised in 2016. As part of the stepwise measures toward nearly zero-energy buildings (NZEBs), the measures state that the primary energy of building permits submitted after January 1, 2016, should not exceed $75 \%$ of the reference building's required amount, and the NRE allocation criteria for new buildings under the Renewable Energy Heat Act were added in 2009. Germany has also set the target of 100\% smart meter use by 2020 in pursuit of EU guidelines [4]. France has set a mandatory Bâtiments à Energie POSitive (BEPOS) standard rather than benchmarking ZEBs as the final target and the enforcement for this will begin for new buildings from 2020. This standard state the energy used for a building should not exceed the required energy amount of a reference building (BEPOSmax) and satisfy a certain amount of energy produced using NRE [5]. Japan has launched the "Research Institution for ZEB Achievement and Distribution" in May 2009 to investigate a detailed measurement in the pursuit of ZEBs and to build zero-energy houses (ZEHs), thereby proposing an overall ZEB vision. The Japanese quantitative definition of ZEB is as follows. First, buildings must not exceed more than $50 \%$ of the primary energy consumption based on a reference building, except for a building in which renewable energy was saved (zero-energy building ready level). Second, buildings must save more than $100 \%$ of the primary energy consumption through the use of NREs or achieve a $50 \%$ reduction of the primary energy consumption by adding NREs [6]. In the USA, the Obama administration aimed for residential ZEBs by 2020, and non-residential ZEBs by 2025 , focusing on the increase in clean energy sources through the "All of the Above Energy Strategy" policy and a stable energy supply through demand management, and this policy has been adapted and promulgated by individual states as verified in the NBI Code and Policy. For example, the state of California targeted ZEBs for new residential buildings by 2020 and non-residential buildings by 2030. [7].

\subsection{Objectives of the Study}

This study aims to define ZEBs in accordance with the technical and economic circumstances in Korea and to describe the study methodology for establishing the mandatory policies and criteria to this end. It also aims to investigate the characteristics of certified buildings through case analyses on zero-energy-certified buildings.

\section{Main Body}

\subsection{Mandatory ZEB Road Map}

There are two methodologies to achieve ZEBs: a passive methodology to reduce the energy used in the building as much as possible and an active methodology that increases the use of NRE, thereby replacing fossil fuel sources with NRE sources, at least to the specified minimal energy used in buildings. The Ministry of Land, Infrastructure, and Transport in the Korean government supervises the direction to reduce the required energy amount used in buildings, and the Ministry of Trade, Industry and Energy plays a leading role in reducing the use of fossil fuels through the promotion of NRE projects. Figure 1 shows the roles of the government ministries for ZEBs. 


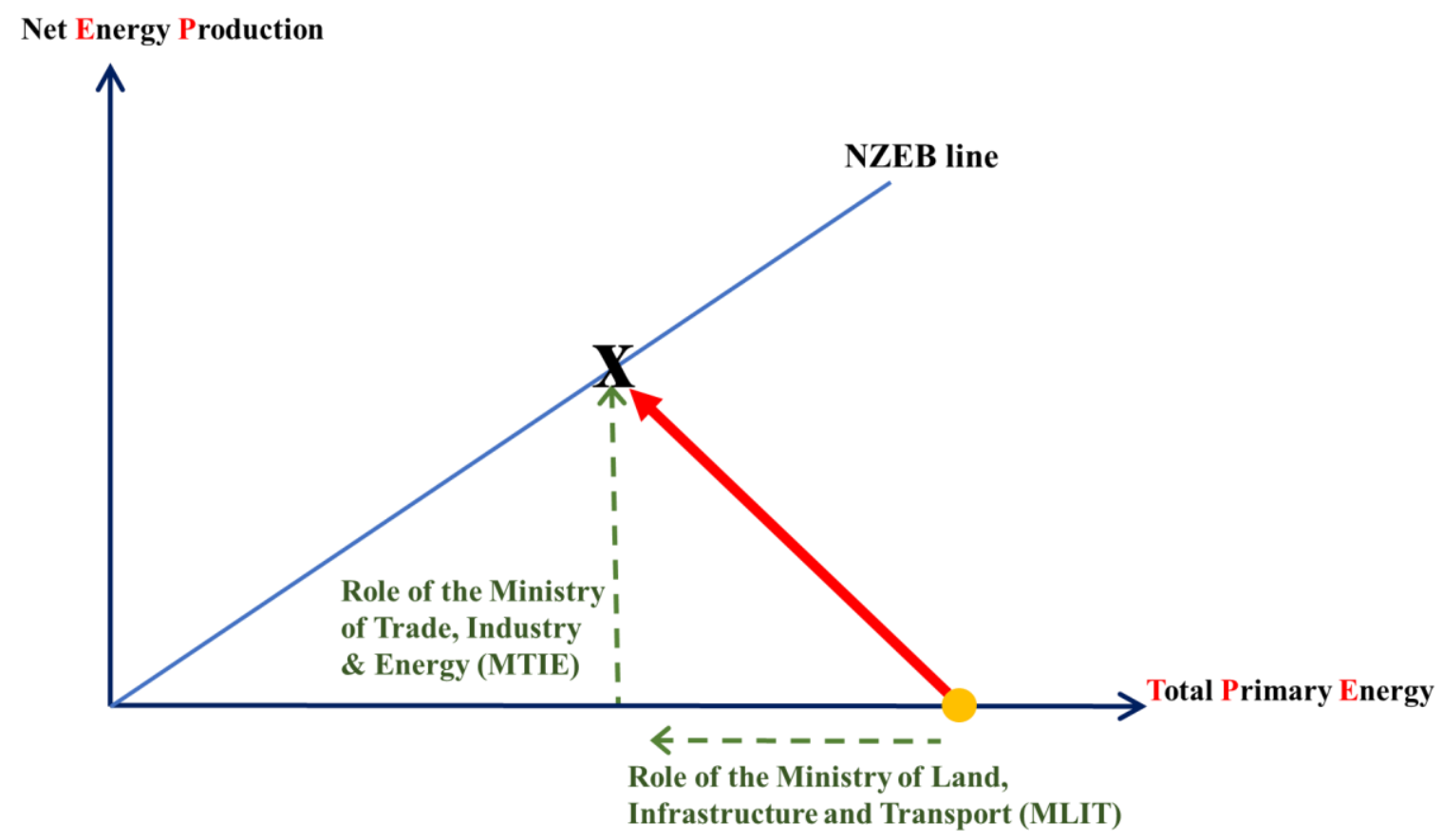

Figure 1. Roles of the government ministries for zero-energy buildings (ZEBs).

To play these roles, the Ministries have announced a mandatory road map for ZEBs through a mandatory certification promotion basis by amending the Green Building Creation Support Act in April 2019 [8]. Since ZEB standards in Korea are positioned under the Green Building Construction Support Act, a building that satisfies the energy requirements in addition to the requirements of the environmental elements, which belong to the part of the general green building definition, are also defined as a green building. Figure 2 shows the mandatory road map for ZEBs from 2017 to 2030 . From 2017 to 2019, market acceptability and problems associated with ZEBs were identified through pilot projects, through the step-by-step mandatory ZEBs implementation according to the area and building purpose from 2020. Korea ultimately targets mandatory ZEBs for all new buildings and additional building extensions whose area is $500 \mathrm{~m}^{2}$ or greater by 2030 .

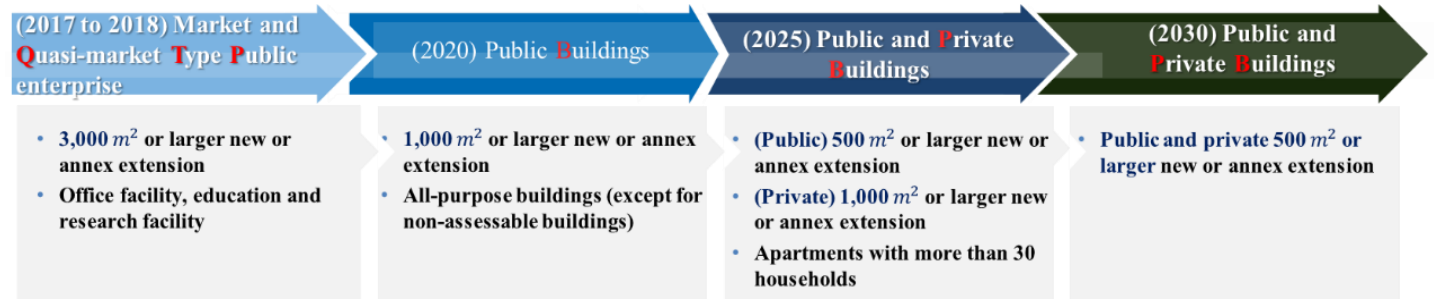

Figure 2. Road map of mandatory zero-energy buildings [8].

\subsection{Certification System of Building Energy in Korea}

\subsubsection{Building Energy Efficiency Rating}

The certification system of the building energy-efficiency ratings in Korea was established in 2001 and this assessed the energy-saving rate of buildings and the required energy-saving amounts to assign and certify the energy-efficiency ratings to the building. Since then, the certificate ratings have been re-evaluated based on the total energy saving rate compared to that of a standard house built in 2010. However, with the enactment of the Green Building Creation Support Act in 2013, the building energy-efficiency rating certificate applications filed after September 2013 were evaluated based on the 
non-renewable primary energy per unit area using the $\mathrm{ECO} 2$ software, which is a quantitative energy simulation tool [9].

Similar to other advanced building energy nations, such as Europe, the USA, and Japan, Korea has implemented a stepwise market direction toward ZEBs as the national direction rather than establishing an immediate regulation requiring net-zero-energy buildings in the current market.

To assess whether buildings comply with the direction, this study aims to minimize the confusion of the system by designing an assessment system that can be used for existing building energy assessment and a ZEB existing building energy-efficiency rating system.

\subsubsection{ECO2, a Building Energy Assessment Tool}

The ECO2 program provides a building energy assessment technique based on ISO 13790 and DIN V18599 [10] and quantitatively evaluates five items: heating, cooling, lighting, hot water, and ventilation systems, based on monthly mean weather data, and which is used in the building's energy-efficiency rating system [11]. The assessment results of the five items in ECO2 are calculated to determine the energy need, the energy use, non-renewable primary energy (NRPE), renewable primary energy (RPE), and the total primary energy. The primary energy conversion coefficient to calculate the primary energy is 1.1 for fuel, 2.75 for electricity, 0.728 for district heating, and 0.937 for district cooling, in which weights according to the usage profile and the heating method are applied to calculate the NRPE for the final rating. The default values are provided according to building use time, operating time, minimum inflow of outdoor air, required hot water amount, lighting time setting, heat-producing sources from persons and work auxiliary equipment, cooling and heating indoor air temperature, and the number of use days in a month. For weather data, standard profiles are retrieved from the ECO2 server to set the outdoor air temperature and the horizontal and vertical global radiations for any of the 13 regions in Korea. For the weather data of ECO2, monthly mean values are calculated based on weather data according to the typical meteorological year (TMY) methodology [12]. Four NRE inputs (geothermal, solar photovoltaic, solar thermal, and combined heat and power) can be entered, and when calculating the NRPE, the RPE amount is deducted from the cooling, heating, hot water, lighting, and ventilation items from the primary energy.

The calculated results have 10 labels, presented in Table 1, for the annual non-renewable primary energy per unit area for the rating, which are divided into residential and non-residential buildings [13].

Table 1. Building energy-efficiency rating table.

\begin{tabular}{|c|c|c|}
\hline \multirow{2}{*}{ Label } & \multicolumn{2}{|c|}{ Annual Non-Renewable Primary Energy $\left(\mathrm{kWh} / \mathrm{m}^{2}\right)$} \\
\hline & Residential Buildings & Non-Residential Buildings \\
\hline $1+++$ & Under 60 & Under 80 \\
\hline $1++$ & More than 60 and under 90 & More than 80 and under 140 \\
\hline $1+$ & More than 90 and under 120 & More than 140 and under 200 \\
\hline 1 & More than 120 and under 150 & More than 200 and under 260 \\
\hline 2 & More than 150 and under 190 & More than 260 and under 320 \\
\hline 3 & More than 190 and under 273 & More than 320 and under 380 \\
\hline 4 & More than 230 and under 270 & More than 380 and under 450 \\
\hline 5 & More than 270 and under 320 & More than 450 and under 520 \\
\hline 6 & More than 320 and under 370 & More than 520 and under 610 \\
\hline 7 & More than 370 and under 420 & More than 610 and under 700 \\
\hline
\end{tabular}

\subsection{Study on Definition of ZEBs in Korea}

\subsubsection{Definition of ZEB Level}

The definition of a ZEB in Korea is a green building that minimizes energy loads and minimizes the required energy amount by utilizing NREs according to the Green Building Creation Support Act, which was amended in 2017 [14]. 
To define the mandatory rating level of zero energy according to the 2020 road map, this study aimed to define the 2017 NZEB (nearly zero-energy building) levels using the database of building energy-efficiency ratings from the Korea Energy Agency. Figure 3 shows the analyzed data of the energy levels in 300 public buildings that had the building energy efficiency rating certificates issued from 2010 to 2015. In the left figure of Figure 3, the NRPE was distributed between $80 \mathrm{kWh} / \mathrm{m}^{2}$, which was Rating $1+++$, to $320 \mathrm{kWh} / \mathrm{m}^{2}$, which was Rating 2 . All the certified energy ratings for the public buildings were a Rating 2 or higher.

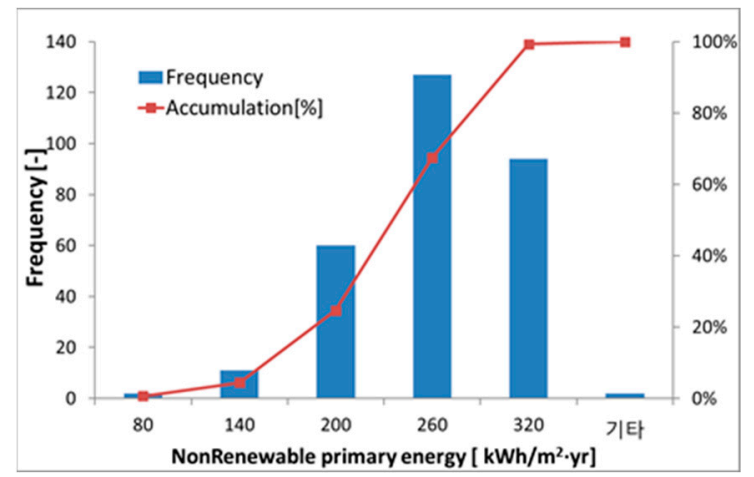

(a)

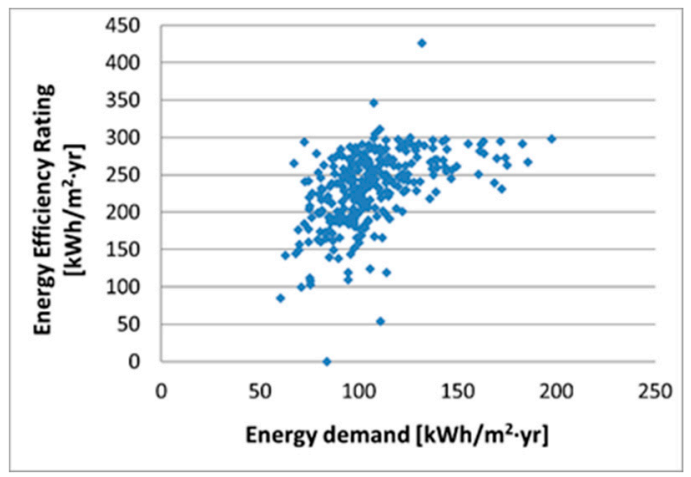

(b)

Figure 3. (a) Energy level of the efficiency rating of buildings, and the frequency of certification by rating (b) distribution of the non-renewable primary energy (NRPE).

The range of energy performance that can be achieved depends on the minimum amount of effort according to expert opinions to reach the same standards as those buildings in the top 5\%, and are based on the NRPE per unit area in the elements: heating, cooling, hot water supply, lighting, and ventilation. The mandatory level of ZEBs were restricted to $138 \mathrm{kWh} / \mathrm{m}^{2}$. This value corresponds to a building energy-efficiency rating of $1++$. To define the level of ZEBs, the energy amount produced by the new and renewable sources of energy is also highly meaningful in addition to the NRPE. Thus, a mandatory level in relation to a certain amount of NRE production at a nearly zero-energy level was important. Thus, the production of NRE in buildings whose rating was $1++$ was found to be below $20 \%$ of the total consumption.

\subsubsection{Level of ZEB Certification}

The $1++$ level of the energy-efficiency rating, which was the top $5 \%$ of buildings considering the energy-efficiency ratings, was based on the five energy elements: heating, cooling, hot water, lighting, and ventilation, and defined as the minimum certificate level for the meeting the definitions of a ZEB in Korea and had to satisfy an energy self-sufficiency rate, which represents the NRE production compared to fossil-fuel energy use. This was added to achieve the link with NRE at sites where buildings are being constructed.

Figure 4 shows the diagram of the ZEB rating levels. This figure depicts the compatibility between the current building energy efficiency ratings and a zero-energy rating, in which ZEB 5 was defined as the minimum rating of ZEBs that corresponds to the current building energy-efficiency rating of 1++, as well as satisfying the $20 \%$ or more NRE production requirement. As the NRE production increased, the zero-energy rating was raised. This is a methodology that can improve the certification level from NZEB (ZEB 5) to NZEB (ZEB 1). 


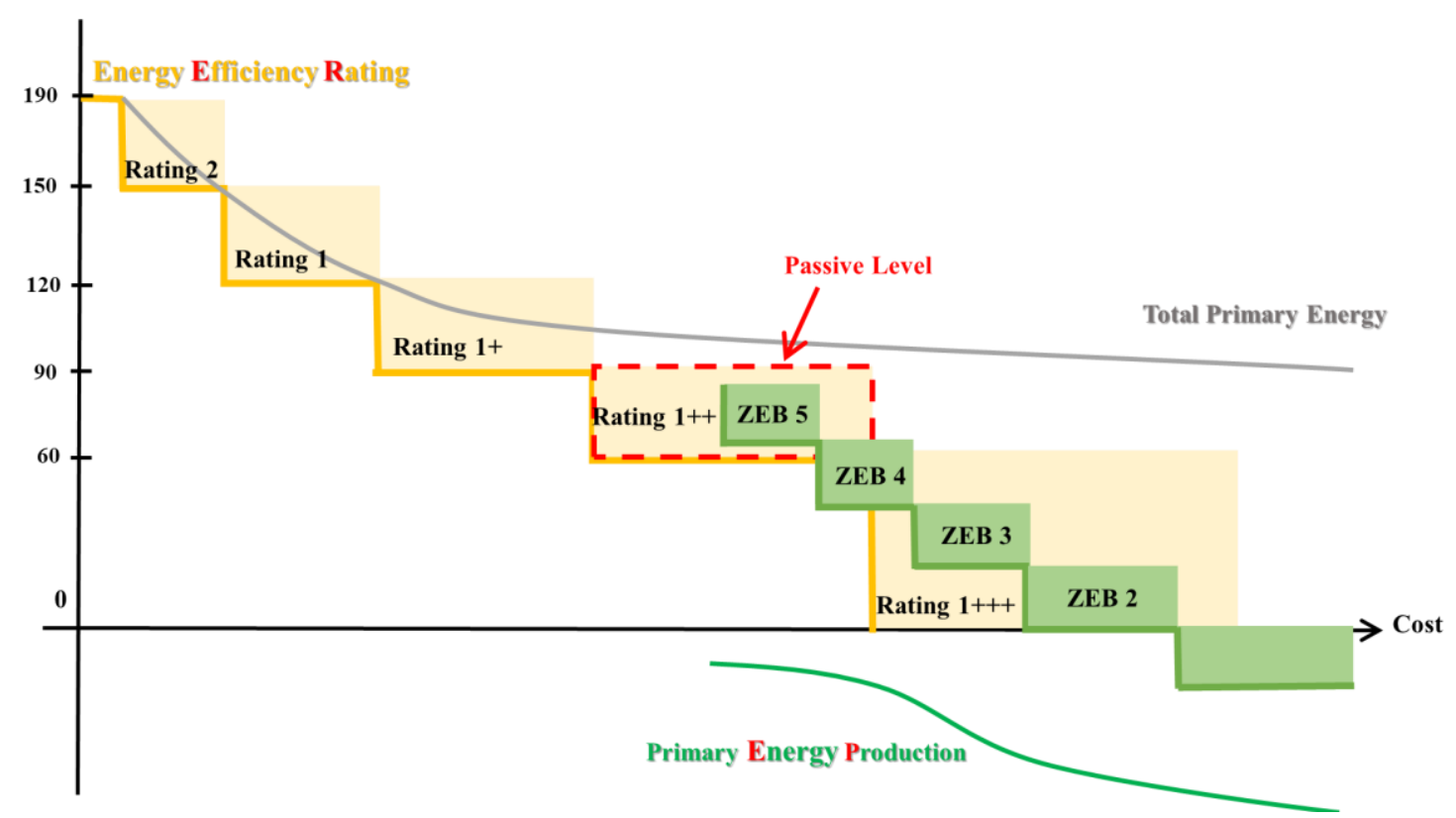

Figure 4. Rating level of the zero-energy buildings.

\subsubsection{Total Primary Energy, NRPE, RPE, and Energy Self-Sufficiency Rate}

When the level (target of the building energy-efficiency rating) of the reduction of the total primary energy is as great as possible in the building elements, the building is defined as having achieved the passive level as shown in Figure 4, thus satisfying the stepwise ZEB rating through the promotion of NREs and would, therefore, allow the building to acquire a ZEB certification. The concept of the energy self-sufficiency rate is defined as RPE (renewable primary energy) compared to the total primary energy, which is an indicator of the NRE performance and is evaluated using a stepwise rating system. Here, the energy self-sufficiency rate was calculated by determining the ratio of the RPE as compared to the total primary energy per unit area, and the total primary energy was a sum of the required fossil fuel energy (NRPE: non-renewable primary energy) and the NRE production (RPE: renewable primary energy) in the building. This is equivalent to the concept of the required building energy in the existing building energy efficiency rating system and is calculated by subtracting the NRE production from the energy amount (energy consumption) used in the entire building.

RPE refers to the energy production produced through NRE systems, excluding the fossil-fuel energy used to drive the system. For example, in the case of a geothermal heat pump shown in Figure 5, the value of the heat production produced by the system, and excluding the energy consumption for the pump working power and the driving power of the heat pump, is accepted as the energy production. This can be expressed by the following equation.

$$
\text { Energy self }- \text { sufficiency rate }(\%)=\frac{\text { RPE per unit area }}{\text { Total primary energy per unit area }} \times 100 \text {. }
$$

Note (1): RPE (renewable primary energy per unit area $\left(\mathrm{kWh} / \mathrm{m}^{2}\right)$

$=\sum(($ NRE production - energy amount required to produce NRE $) \times$ corresponding primary energy conversion coefficient)/evaluated area.

Note (2): Total primary energy per unit area $\left(\mathrm{kWh} / \mathrm{m}^{2}\right)$

$=$ Non-renewable primary energy (NRPE) per unit area + renewable primary energy $(\mathrm{RPE})$ per unit area. 


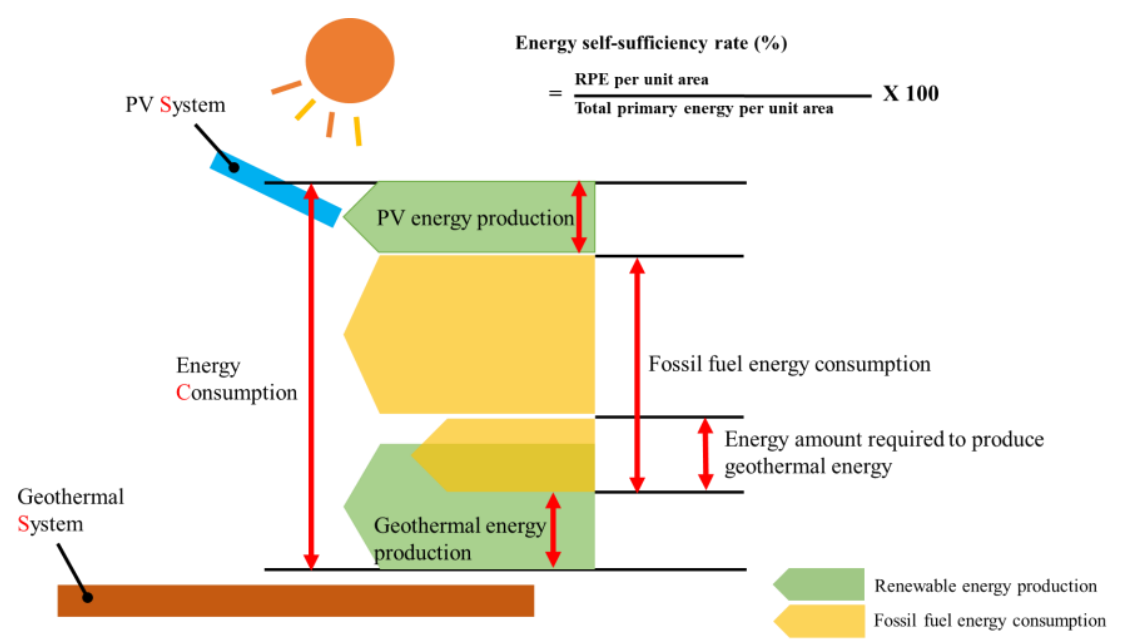

Figure 5. Flow diagram of the components for the self-sufficiency rating by renewable energy source.

\subsubsection{Other Certification Criteria of ZEBs}

The current mandatory system of ZEBs is based on the limited building performance under the standard conditions. Thus, this study added a criterion of the mandatory installation of BEMS by which energy usage can be read or electronic meters can allow constant remote reading of a meter for each energy source to investigate the operating conditions of the buildings or the operating patterns of the residents in the future. Thus, the final certification criteria of the ZEBs are shown in Figure 6.

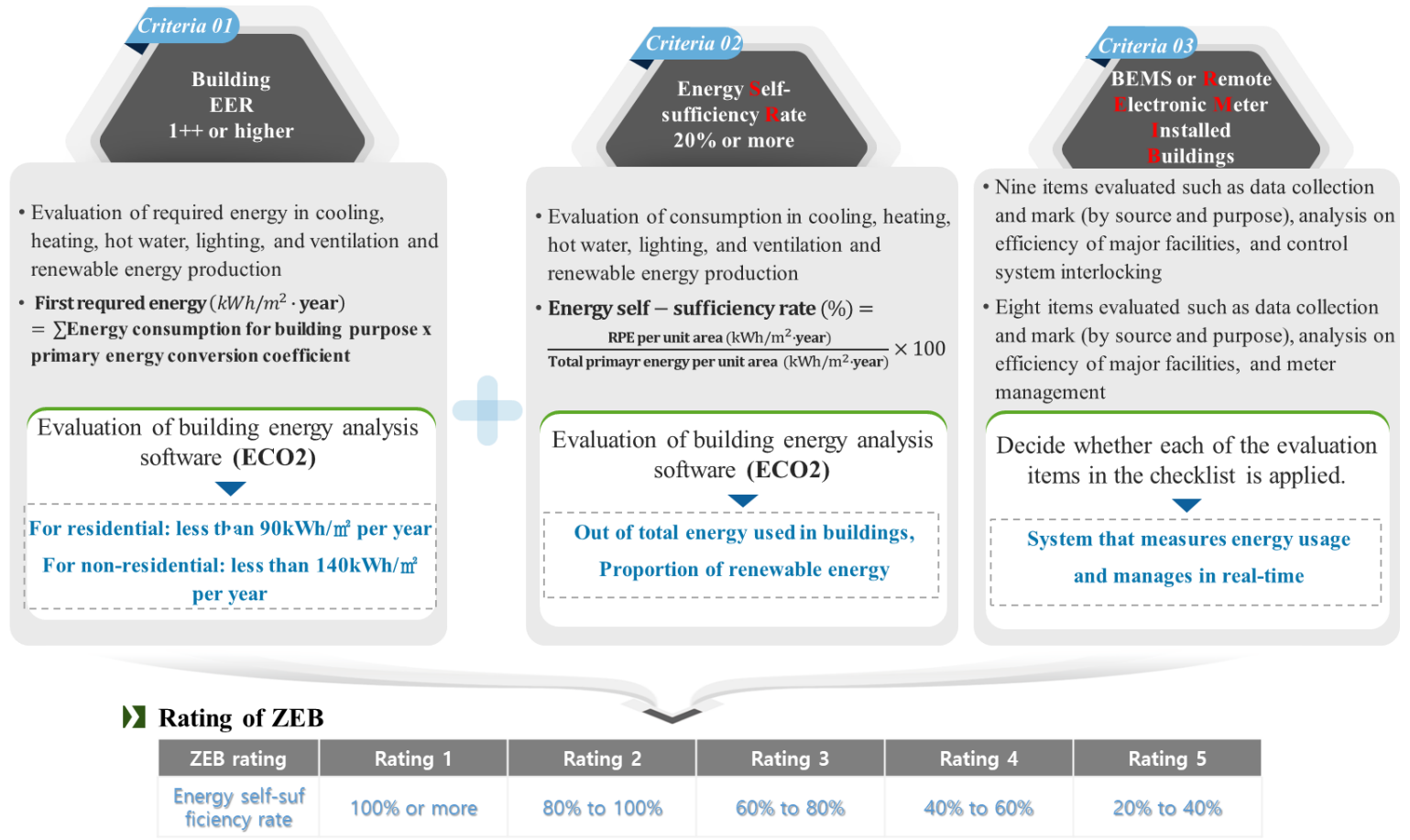

Figure 6. ZEB certification criteria.

\subsection{Current Status of ZEB Certification}

To analyze the ZEB certification trends through pilot projects prior to making the ZEB certification mandatory in 2020, the current status of the buildings certified as a ZEB in 2017 to 2019 was analyzed [15]. The number of certificates for three years, as presented in Table 2, was 83, in which nine cases were for residential buildings and 75 cases were for non-residential buildings, showing a much greater 
number of certificates issued for non-residential buildings. This was because the mandatory target was concentrated on market-type public companies and residential buildings were affected by only the pilot complex project. The proportion of Rating 5, which is the minimum criterion of the mandatory level, was $74 \%$ (64 cases). The higher ratings had smaller numbers of certified cases.

Table 2. Current status of ZEB certificates.

\begin{tabular}{cccccc}
\hline Rating & Rating 5 & Rating 4 & Rating 3 & Rating 2 & Rating 1 \\
\hline No. of certificates (-) & 64 & 11 & 8 & 1 & 3 \\
Proportion (\%) & 74 & 13 & 9 & 1 & 3 \\
\hline
\end{tabular}

The comparison results of the NRPE and RPE, which were two of the five energy elements, are considered according to each rating as shown in Figure 7, and indicated that the primary heating energy was reduced by $59.2 \%$ from $69.7 \mathrm{kWh} / \mathrm{m}^{2}$ to $28.4 \mathrm{kWh} / \mathrm{m}^{2}$ as the rating was raised from Rating 1 to ZEB 5; the primary cooling energy was reduced by $69.38 \%$ from $58.6 \mathrm{kWh} / \mathrm{m}^{2}$ to $17.7 \mathrm{kWh} / \mathrm{m}^{2}$; and the primary lighting energy was reduced by $54.2 \%$ from $46.7 \mathrm{kWh} / \mathrm{m}^{2}$ to $21.4 \mathrm{kWh} / \mathrm{m}^{2}$. The primary ventilation energy was reduced by $64 \%$ from $43.8 \mathrm{kWh} / \mathrm{m}^{2}$ to $15.8 \mathrm{kWh} / \mathrm{m}^{2}$, and the RPE increased by $403 \%$ from $6.5 \mathrm{kWh} / \mathrm{m}^{2}$ to $32.6 \mathrm{kWh} / \mathrm{m}^{2}$. These results indicated that a total sum of the primary energy was reduced by more than $50 \%$ whereas the NRE production more than quadrupled as the rating was raised.

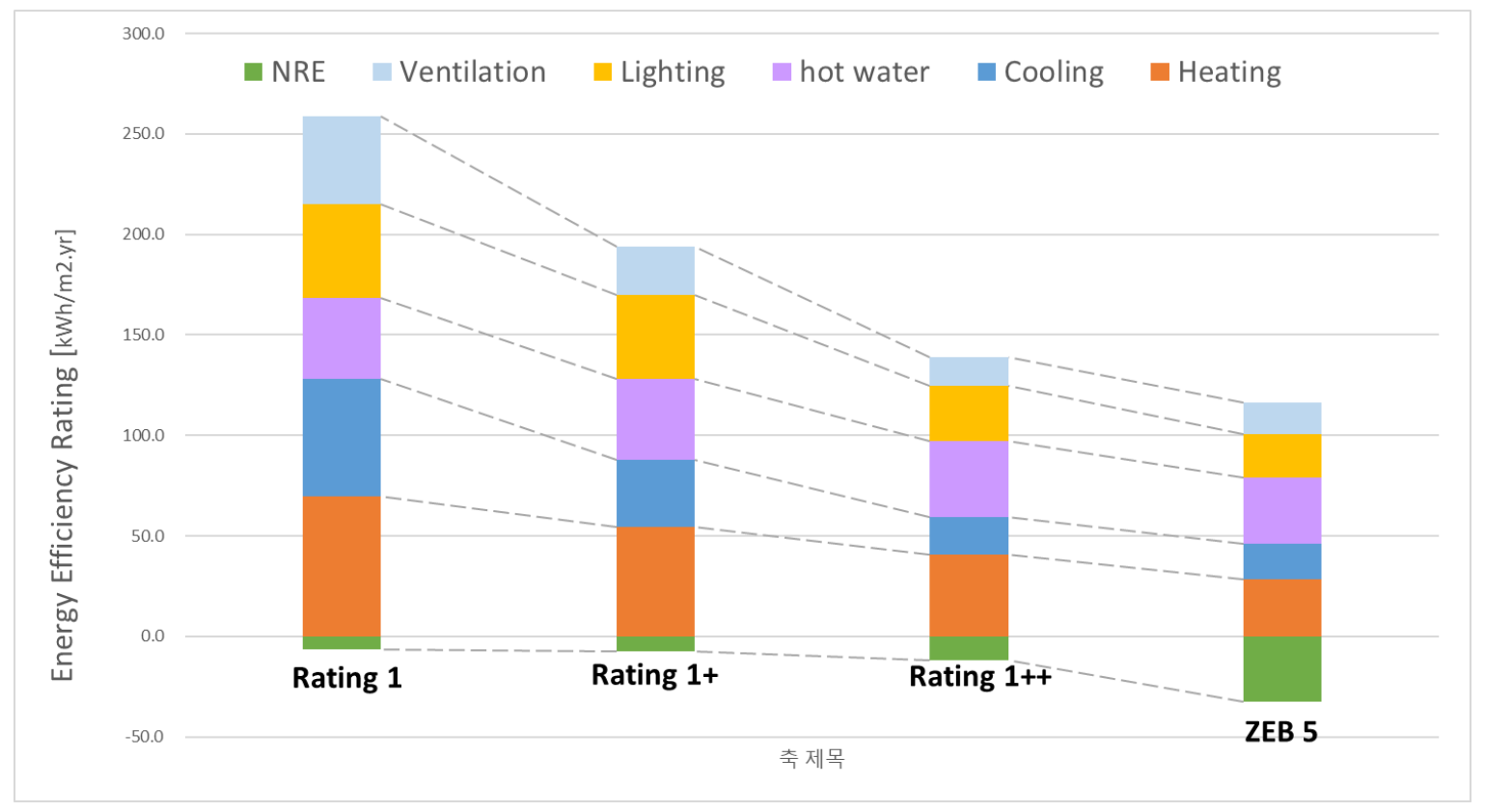

Figure 7. Five energy elements according to the certification criteria, NRPE, and RPE.

This can be seen as an increase in production as the installed NRE capacity increased according to the rating level as shown in Figure 8.

To install the NRE to increase the RPE, sites must be provided. Currently, NRE is accepted only when it is produced on-site in Korea. Thus, those energy sources are accepted when considering the primary energy coefficient. Thus, for all 83 ZEB certification cases, photovoltaic systems were installed as the NRE source. This is due to the fact that the primary energy conversion coefficient of the electricity (2.75) was multiplied, adding to the convenience of installation and price competitiveness. However, as mentioned in the above, since only on-site installation was accepted, the self-sufficiency rating level (level of certification rating) tended to be inversely proportional to the total area, as shown in Figure 9. 


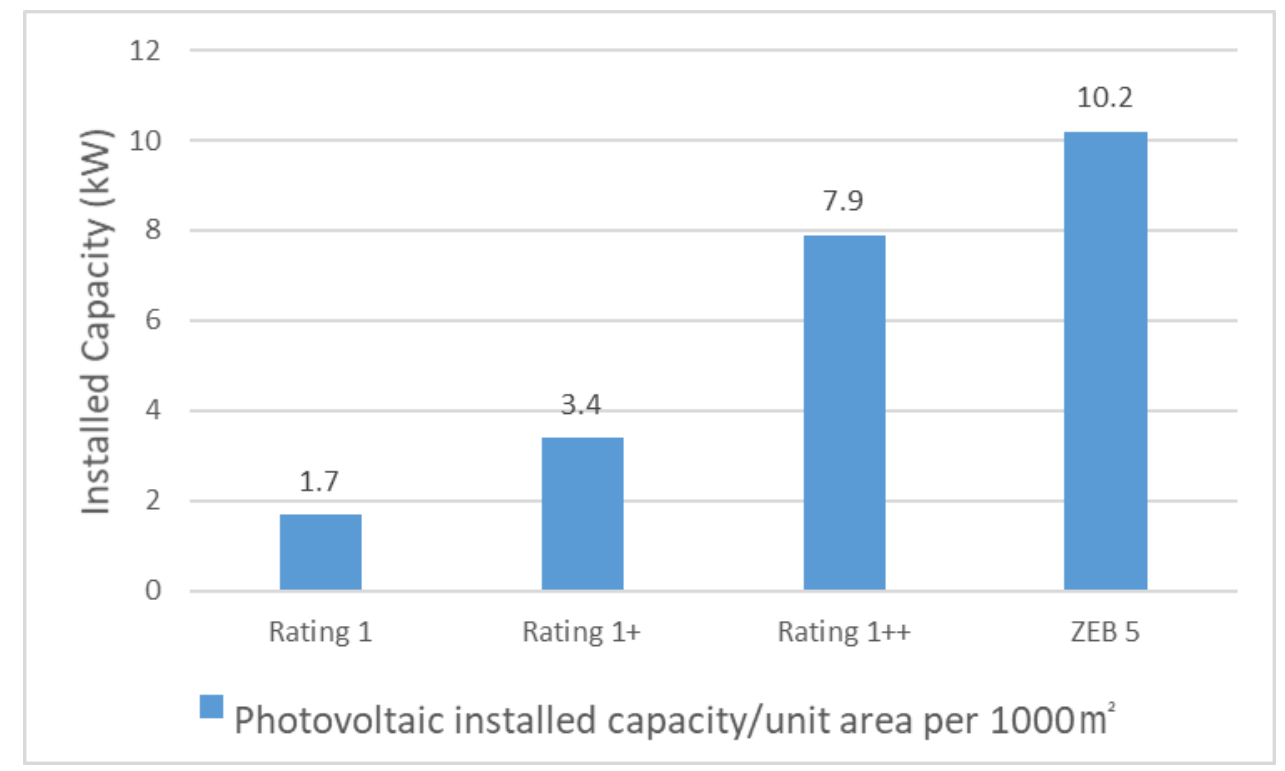

Figure 8. Photovoltaic installed capacity according to the ZEB rating.

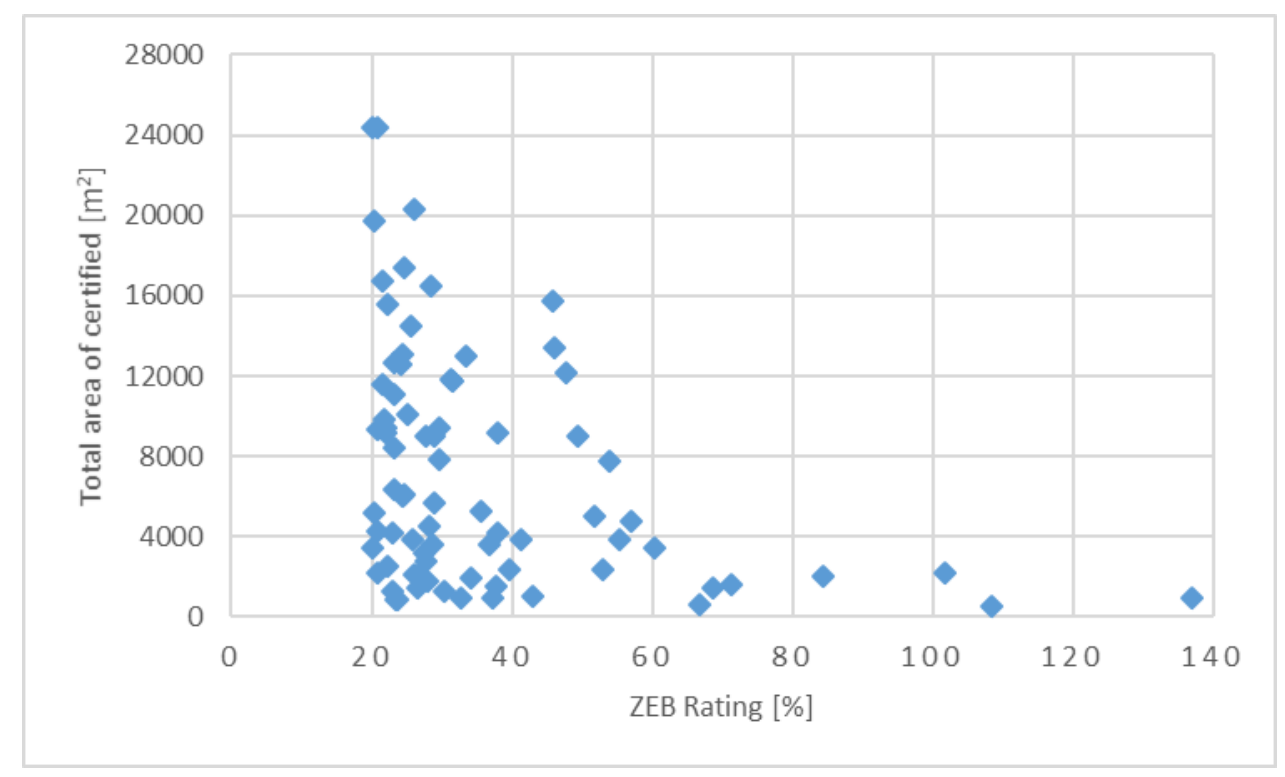

Figure 9. ZEB rating according to the total area of certified buildings.

\section{Conclusions}

This study proposed the definition of a ZEB and certification levels that complied with the definition of the International Zero-Energy Building and is relevant in Korea. This study also analyzed the current status of the buildings that acquired ZEB certification. The study results are summarized as follows:

(1) The ZEB certification in Korea proposes a stepwise certification level that can be certified from the nearly ZEB (NZEB) level to a plus level. The rating level of the ZEB was defined as those meeting a $1++$ building level, which were the top $5 \%$ of buildings based on the existing building energy efficiency rating database.

(2) The rating was defined as satisfying the passive level of the building and differentiating the NRE production. The rating was assigned for every $20 \%$ section based on the NRE self-sufficiency rate, which is determined through the total primary energy, non-renewable primary energy (NRPE), renewable primary energy (RPE), and the self-sufficiency rate. 
(3) The current certification status of the ZEBs in Korea exhibited that as the rating increased, the total sum of the required first energy amount was reduced by $50 \%$ in the case of Rating ZEB 1 compared to that of Rating 1++ of building energy-efficiency rating, and the NRE production more than quadrupled.

(4) The NRE self-sufficiency rate level (level of certification rating) was inversely proportional to the total area, which showed a limitation according to the building environments since the ZEBs in Korea are evaluated based on the NRE produced only on-site.

For future studies, constant methodology developments of off-site evaluations in addition to on-site evaluations are needed, and a study on measures to extend the currently limited certification assessment in heating, cooling, hot water supply, lighting, and ventilation into other areas, such as household appliances and transportation, is also needed.

Author Contributions: Y.K. analyzed the study outcomes; K.-H.Y. conceived the concept. All authors have read and agreed to the published version of the manuscript.

Funding: This research was funded by [Infrastructure and Transport of the Korean government] grant number [19AUDP-B079104-06].

Acknowledgments: This research was supported by a grant (19AUDP-B079104-06) from Architecture \& Urban Development Research Program funded by Ministry of Land, Infrastructure and Transport of the Korean government.

Conflicts of Interest: The authors declare no conflict of interest.

\section{References}

1. International Energy Agency. Energy Policies of IEA Countries-The Republic of Korea 2012 Review; International Energy Agency: Paris, France, 2012.

2. Concerted Action EPBD. 2016 Implementation the Energy Performance of Buildings Directive (EPBD): Featuring Country Reports; ADENE: Lisboa, Portugal, 2015; p. 594. Available online: https://epbd-ca.eu/ca-outcomes/ 2011-2015 (accessed on 20 April 2020).

3. Danish Transport and Construction Agency. Danish Building Regulations 2015, 2015.12; Danish Transport and Construction Agency: Copenhagen, Denmark, 2015.

4. Feist, W. Lernzielkatalog "Zertifizierter PassivhausPlaner"; Passive Haus Institute: Darmstadt, Germany, 2015.

5. IPEEC. Building Energy Efficiency Requirements in Building Codes, Energy Efficiency Policies for New Buildings; International Energy Agency (IEA): Paris, France, 2008; pp. 477-488.

6. Cui, C.; Niu, J.J. Energy-saving technology strategy 2011 and Enlightenment to us. Energy China 2011, 33, $10-14$.

7. American Society of Heating, Refrigerating, and Air-Conditioning Engineers. ANSI/ASHRAE/IES Standard 90.1-2016: Energy Standard for Buildings Except Low-Rise Residential Buildings; ASHRAE: Atlanta, GA, USA, 2016.

8. Joint Related Ministries. 2030 Modification \& Complementation of the Greenhouse Gas Reduction Roadmap; Ministry of Environment: New Delhi, India, 2018; p. 3.

9. Green Buildings Construction Support Act No. 16418. Available online: http://www.law.go.kr/lsSc.do? tabMenuId=tab18\&section=\&eventGubun=060101\&query= $\% E B \% 85 \% B 9 \% E C \% 83 \% 89 \% \mathrm{EA} \% \mathrm{~B} 1 \% \mathrm{~B} 4 \%$ EC\%B6\%95\#liBgcolor0 (accessed on 20 April 2020).

10. Andaloro, A.P.E.; Salomone, R.; Ioppolo, G.; Andaloro, L. Energy certification of buildings: A comparative analysis of progress towards implementation in European countries. Energy Policy 2010, 28, 5840-5866. [CrossRef]

11. Jo, J.-H. A Study on Evaluation Criteria and Evaluation Tool for Energy Performance of internal and external Building, Construction Technique/Sangyong, Special Project II-Zero Energy Building Policies and Trends of Internal and External Building. 2017, p. 23. Available online: http://www.auric.or.kr/User/Rdoc/DocRdoc. aspx?BrsDataBaseName=RDOC\&PrimaryKey=350201\&DBNM=RDCR\#.XvGVO3duKU1 (accessed on 20 April 2020).

12. Kim, Y.; Jang, H.K.; Yu, K.H. Study on Extension of Standard Meteorological Data for Cities in South Korea Using ISO 15927-4. Atmosphere 2017, 8, 220. [CrossRef] 
13. Certification Standards of Building Energy Efficiency Rating and Zero Energy Building, Annexed Table 2. In Notice No. 2018-675 of the Ministry of Land, Infrastructure and Transport. Available online: http: //www.law.go.kr/admRulSc.do?tabMenuId=tab107\&query=\%EA \%B1\%B4\%EC\%B6\%95\%EB\%AC\%BC\% EC $\% 97 \% 90 \%$ EB $\% 84 \% 88 \%$ EC $\%$ A7\%80\%20\%ED\%9A\%A8\%EC\%9C\%A8\%EB\%93\%B1\%EA\%B8\%89\#AJAX (accessed on 20 April 2020).

14. Ministry of Land. The Second Green Building Basic Plan, Green Architecture Division. 2020; pp. 1-12. Available online: http://www.molit.go.kr/USR/NEWS/m_71/dtl.jsp?id=95083381 (accessed on 20 April 2020).

15. Zero-Energy Building Information Site in Korea Energy Agency. Available online: https://zeb.energy.or.kr/ BC/BC00/BC00_01_001.do (accessed on 20 April 2020).

(C) 2020 by the authors. Licensee MDPI, Basel, Switzerland. This article is an open access article distributed under the terms and conditions of the Creative Commons Attribution (CC BY) license (http://creativecommons.org/licenses/by/4.0/). 